\title{
Frontières
}

\section{L’aide médicale à mourir}

\section{Jocelyne Saint-Arnaud}

Volume 24, numéro 1-2, automne 2011, printemps 2012

L’aide médicale à mourir

URI : https://id.erudit.org/iderudit/1013078ar

DOI : https://doi.org/10.7202/1013078ar

Aller au sommaire du numéro

Éditeur(s)

Université du Québec à Montréal

ISSN

1916-0976 (numérique)

Découvrir la revue

Citer ce document

Saint-Arnaud, J. (2011). L'aide médicale à mourir. Frontières, 24(1-2), 7-8.

https://doi.org/10.7202/1013078ar

Ce document est protégé par la loi sur le droit d'auteur. L'utilisation des services d'Érudit (y compris la reproduction) est assujettie à sa politique d'utilisation que vous pouvez consulter en ligne.

https://apropos.erudit.org/fr/usagers/politique-dutilisation/
Cet article est diffusé et préservé par Érudit.

Érudit est un consortium interuniversitaire sans but lucratif composé de l’Université de Montréal, l'Université Laval et l'Université du Québec à Montréal. Il a pour mission la promotion et la valorisation de la recherche. https://www.erudit.org/fr/ 


\section{L'AIDE MÉDICALE À MOURIR}

Jocelyne Saint-Arnaud, Ph. D. (philosophie),

codirectrice du numéro.

L'idée d'un numéro sur l'aide médicale à mourir est venue avec l'organisation d'un colloque interdisciplinaire ayant pour titre: «L'aide médicale au suicide et l'euthanasie: enjeux éthiques et impacts sur les pratiques». Ce colloque organisé par la revue Frontières a eu lieu en mai 2010 dans le cadre du congrès de l'Acfas à l'Université de Montréal. Des conférenciers ont soumis leur texte discutant d'une question qui a préoccupé tant les organisations savantes et gouvernementales que le public par la suite: la légalisation des pratiques d'euthanasie et d'aide au suicide. Aux auteurs québécois se sont joints des auteurs belges témoignant des pratiques actuelles dans ce pays qui a légalisé l'euthanasie en 2002. Il s'agit donc d'un numéro à deux voix: celle de Jocelyne Saint-Arnaud, pour le Québec, et celle de Marie-Luce Delfosse, pour la Belgique, toutes deux responsables du numéro.

Ouvrant le numéro, Jocelyne Saint-Arnaud explore ce que signifie l'expression «mourir dans la dignité», d'abord selon le point de vue d'une anthropologie philosophique, puis selon des théories éthiques non traditionnelles. Ainsi, le déontologisme kantien, le situationnisme, l'utilitarisme et l'approche bioéthique sont interrogés sur ce qu'est la dignité humaine en relation avec la moralité de l'aide au suicide et de l'euthanasie. Une analyse cri- tique montre que la déontologie kantienne refuse toute moralité à des actes comme l'aide au suicide et l'euthanasie; cependant, les autres théories étudiées considèrent que ces actes pourraient être moralement acceptables à certaines conditions. Dans son article, Michel Giroux examine en profondeur la position qu'avait adoptée la Commission de réforme du droit du Canada (CRDC) dans son rapport publié en 1982 et intitulé: Euthanasie, aide au suicide et interruption de traitement. Il en précise les présupposés philosophiques et juridiques, de même que les normes d'application des articles du Code criminel en cause. Il compare ensuite cette position à celle tenue par la députée Francine Lalonde dans son projet de loi, mort au feuilleton en 2010, visant à dépénaliser l'euthanasie volontaire. Son analyse et ses conclusions montrent que, mis à part la cessation de traitement qui ne fait plus problème dans la pratique médicale aujourd'hui, les arguments amenés par la CRDC sont toujours pertinents dans le débat actuel.

Compte tenu du fait que la «majorité des décès découlent maintenant d'une prise de décision clinique", un groupe de travail du Collège des médecins du Québec s'intéresse aux soins de fin de vie depuis 2005. Dans un article fort éclairant, Michèle Marchand explique la démarche qui a conduit le Collège à étudier les processus décisionnels en fin de vie, ne fermant pas la porte à la possibilité que l'euthanasie puisse être considérée exceptionnellement comme l'étape ultime des soins appropriés en 
fin de vie. Loin de considérer que l'éthique médicale s'oppose à cela, il y aurait même une obligation déontologique à pratiquer l'euthanasie dans certaines circonstances. Ceci étant dit, les soins appropriés demeurent ceux qui sont issus de processus décisionnels bien menés et de décisions partagées.

Faisant suite aux enquêtes menées auprès de la population en général, de médecins omnipraticiens et de médecins spécialistes pour connaître leur opinion sur l'aide au suicide et l'euthanasie, Valérie Chamberland publie dans la section Recherche les résultats d'une enquête effectuée auprès des travailleurs sociaux du Québec sur le même sujet. Les questions posées ont trait notamment à la moralité de l'aide au suicide et de l'euthanasie volontaire, au nombre de demandes reçues et aux difficultés rencontrées. Les résultats de cette enquête montrent que les travailleurs sociaux sont favorables à ces deux pratiques dans certaines conditions.
Dans la section Points de vue, Éric Volant dresse un portrait des thèmes abordés dans les débats suscités lors des auditions publiques de la Commission spéciale sur la question de mourir dans la dignité. Par ailleurs, Marcel Boisvert nous livre ses réflexions tous azimuts sur la mort en fin de vie. Enfin, une conférence prononcée dans le cadre du récent Congrès de la Société canadienne de bioéthique a retenu notre attention au point d'en publier le texte. Il s'agit de la conférence de Dominique Jacquemin portant sur l'éthique et la spiritualité. Ce texte qui clôt le numéro montre les limites des processus décisionnels instaurés par les lois, notamment la loi belge relative à l'euthanasie, et les limites des approches narratives et principielles en éthique clinique. La spiritualité entendue comme mouvement d'existence y apparaît comme un complément nécessaire à la considération et à l'implication de l'humain dans la totalité de son être, en vue de la résolution des problèmes éthiques complexes, tant du côté des soignants que de celui des patients. 